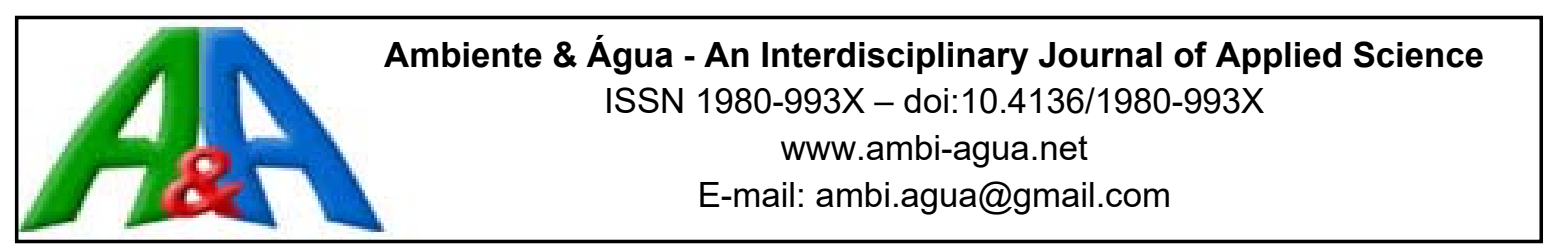

\title{
Diagnóstico espacial e temporal de condições físico-químicas e microbiológicas do Córrego do Tanquinho, Ribeirão Preto, SP, Brasil
}

\author{
doi:10.4136/ambi-agua.1837
}

Received: 09 Jan. 2016; Accepted: 31 Jan. 2017

\author{
Andre Abreu Grieco' ${ }^{1}$; Brisa Maria Fregonesi ${ }^{1}$; \\ Karina Aparecida de Abreu Tonani ${ }^{1}$; Thaís Vilela Silva ${ }^{1}$; \\ Beatriz Smidt Celere ${ }^{1}$; Tânia Maria Beltramini Trevilato ${ }^{2}$; \\ Susana Inés Segura-Muñoz ${ }^{1}$; Renato Igor da Silva Alves ${ }^{1 *}$ \\ Universidade de São Paulo (USP), Ribeirão Preto, SP, Brasil \\ Escola de Enfermagem de Ribeirão Preto (EERP) \\ ${ }^{1}$ Departamento de Enfermagem Materno-Infantil e Saúde Pública \\ ${ }^{2}$ Setor de Metais do Hospital das Clínicas \\ *Autor correspondente: e-mail: renatobio_usp@yahoo.com.br, \\ andregrieco11@gmail.com, brisa fregonesi@yahoo.com.br, \\ karina_abreustz@yahoo.com.br, thaiis_vilela@hotmail.com, \\ beacelere@gmail.com,tmbeltra@fmrp.usp.br, susis@eerp.usp.br
}

\section{RESUMO}

O objetivo do estudo foi avaliar as condições fisico-químicas e microbiológicas do Córrego do Tanquinho, localizado em área altamente urbanizada e industrializada no município de Ribeirão Preto, SP, Brasil, considerando variações espaciais e temporais. Os parâmetros limnológicos avaliados foram: $\mathrm{pH}$, temperatura, turbidez, condutividade e oxigênio dissolvido (OD), com medições realizadas in situ. Os níveis de metais no sedimento e em água superficial foram analisados por Espectrofotometria de Absorção Atômica. Para a determinação dos Coliformes Totais e Escherichia coli foi empregada a técnica dos Tubos Múltiplos com utilização de substrato cromogênico. Os parâmetros OD, E. coli e a concentração dos metais $\mathrm{Cu}$ e $\mathrm{Mn}$ na água encontram-se em desacordo com a legislação. Os metais encontrados em maior concentração no sedimento foram $\mathrm{Mn}, \mathrm{Cr}$ e $\mathrm{Zn}$. A avaliação microbiológica evidenciou o despejo de esgoto doméstico no córrego e as concentrações de metais indicam a possível ocorrência de efluentes industriais, podendo gerar graves problemas de saúde pública. $\mathrm{O}$ diagnóstico espacial indicou os locais de amostragem com as piores condições microbiológicas e altas concentrações de metais, enquanto que a influência temporal foi observada no $\mathrm{pH}, \mathrm{Mn}$ e Cr em água superficial, e $\mathrm{Mn}, \mathrm{Cr}$ e $\mathrm{Pb}$ nos sedimentos. Os resultados mostraram que o Córrego do Tanquinho é um corpo hídrico impactado. Recomenda-se a realização de outros estudos que possam esclarecer melhor a origem das cargas poluidoras, além da conscientização da população e da adoção de medidas que possibilitem a recuperação e proteção desse corpo hídrico.

Palavras-chave: água superficial, E. coli, metais, parâmetros limnológicos, sedimento. 


\title{
Spatial and temporal diagnosis of the physicochemical and microbiological conditions of Tanquinho's Stream, Ribeirão Preto, SP, Brazil
}

\begin{abstract}
The aim of the study was to evaluate the physico-chemical and microbiological conditions of Tanquinho's Stream, located in a highly urbanized and industrialized area in Ribeirão Preto, SP, Brazil, taking into account spatial and temporal variations. The following limnological parameters were evaluated: $\mathrm{pH}$, temperature, turbidity, conductivity and dissolved oxygen (DO), with measurements in situ. Metal levels in sediment and surface water were analyzed by Atomic Absorption Spectrometry. The Multiple Tubes technique with chromogenic substrate was used to determine Total Coliforms and Escherichia coli. The parameters of DO, E. coli and the concentration of $\mathrm{Cu}$ and $\mathrm{Mn}$ in the water are not in accordance with national legislation. The metals found in higher concentrations in the sediment were $\mathrm{Mn}, \mathrm{Cr}$ and $\mathrm{Zn}$. The microbiological evaluation showed sewage discharges into the stream and the metal concentrations indicate possible industrial effluents, which may cause serious public health problems. The spatial diagnosis indicated the sampling sites with the worst microbiological conditions and high concentrations of metals, while the temporal influence was observed in the $\mathrm{pH}, \mathrm{Mn}$ and $\mathrm{Cr}$ in surface water, and $\mathrm{Mn}, \mathrm{Cr}$ and $\mathrm{Pb}$ in the sediments. The results indicate that Tanquinho's Stream is an impacted water body. It is recommended that further studies be conducted to clarify the source of pollutants and to assess the degree of public awareness, and that measures be adopted to ensure the recovery and protection of this water body.
\end{abstract}

Keywords: E. coli, metals, limnology parameters, sediment, surface water.

\section{INTRODUÇÃO}

Apesar da grande disponibilidade, a água doce no Brasil não está distribuída de maneira homogênea pelo território nacional. A Região Sudeste concentra $42,65 \%$ da população do país e apenas $6 \%$ dos recursos hídricos, enquanto que a Região Norte abriga 68,50\% dos recursos hídricos e apenas 6,98\% da população (Philippi Jr. e Martins, 2005).

O desenvolvimento das cidades e das atividades humanas podem causar prejuízos significativos para a sociedade, principalmente no que diz respeito à qualidade da água (Mei et al., 2014). Somado à intensa urbanização e à carência de esgotamento sanitário, o processo de industrialização do país contribuiu para um aumento significativo da carga poluidora lançada nos corpos d'água presentes em áreas urbanas (Souza e Andrade, 2014).

O município de Ribeirão Preto está localizado na região Nordeste do Estado de São Paulo e a maior parte do seu território situa-se na Bacia Hidrográfica do Rio Pardo. A bacia do Rio Pardo, cuja drenagem é da ordem de $10.849 \mathrm{~km}^{2}$, abriga um contingente populacional de cerca de 1.108.118 habitantes, sendo Ribeirão Preto o município mais populoso. Caracterizado como um dos mais importantes polos regionais do estado, o município vive um intenso desenvolvimento econômico, com destaque para indústria sucroalcooleira e, mais recentemente, no segmento de alta tecnologia, fator impulsionador do desenvolvimento técnico-científico da região (Ribeirão Preto, 2012).

Os córregos que cortam a cidade de Ribeirão Preto apresentam inúmeras irregularidades, como matas ciliares degradadas e pouca área mínima de recuo. Os corpos d'água também recebem cargas clandestinas de esgoto, além do lixo carregado pelas chuvas ou depositado pela população (Da Silva Alves et al., 2013). O Córrego do Tanquinho, objeto deste estudo, está localizado em área urbana do município de Ribeirão Preto. O córrego possui 7.048,02 m de 
comprimento e bacia hidrográfica de $20,37 \mathrm{~km}^{2}$ de área, densamente povoada e ocupada por notáveis bairros industriais da cidade (Tomazelli et al., 2010).

A hidrobiologia e qualidade da água do Córrego do Tanquinho podem estar comprometidas considerando sua localização no perímetro urbano. Sabe-se que as características naturais dos cursos d'água são alteradas pelo lançamento irregular de efluentes domésticos, erosão das margens e por resíduos depositados diretamente pela população (Purandara et al., 2012).

Nesse cenário de urbanização, sem um correto planejamento ambiental e infraestrutura adequada, acentua-se a diminuição e escassez de recursos hídricos, motivo pelo qual é necessário que se realizem estudos de avaliação e monitoramento da qualidade da água. Tais estudos proveem indicadores e informações que oferecem respaldo para a tomada de decisão com relação ao planejamento ambiental e proteção dos recursos hídricos realizados pelos órgãos de gestão responsáveis. Esses estudos e análises que permitem verificar as concentrações dos poluentes, além das possíveis fontes das cargas poluidoras, são fundamentais para elaboração de políticas de controle de poluição. Recentemente, tais estudos têm ganhado relevância no Brasil e no mundo (Shin et al., 2013).

Em vista disso, o objetivo do presente estudo foi avaliar as condições fisico-químicas e microbiológicas do Córrego do Tanquinho, localizado em uma área altamente urbanizada e industrializada no município de Ribeirão Preto - SP, considerando variações espaciais e temporais.

\section{MATERIAL E MÉTODOS}

\subsection{Local de estudo e coleta de amostras}

O presente trabalho foi desenvolvido no córrego do Tanquinho (Figura 1), cuja nascente está localizada nas proximidades do Parque Industrial Lagoinha, na Região Leste do Município de Ribeirão Preto, SP, Brasil. O córrego cruza os bairros Jardim Anhanguera, Parque dos Bandeirantes, Jardim Paulistano, Jardim Independência, Campos Elíseos, Parque Industrial Tanquinho e deságua no córrego Ribeirão Preto na região norte da cidade. Dessa forma, sua bacia é caracterizada pela alta urbanização, com a presença de bairros populosos e industriais.

Foram selecionados cinco pontos para as coletas das amostras. Não foi possível a coleta na nascente do córrego, já que a mesma se encontra canalizada e sem acesso. O ponto 1 foi escolhido pois é o primeiro local em que é possível ter acesso ao leito do córrego a partir de sua nascente e localiza-se muito próximo a ela. Neste trecho o córrego já se encontra canalizado, ainda assim sua caracterização se destaca dos demais locais de coleta: as margens são mais preservadas por vegetação; a distância para residências e construções é maior; a profundidade, o leito, o fluxo e volume de água são menores que nos demais pontos. É importante salientar que esses parâmetros não foram mensurados e são baseados nas observações realizadas em visitas aos locais.

Os demais locais de coleta, ponto 2 , ponto 3 , ponto 4 e ponto 5 se caracterizam de forma muito semelhante: ausência de vegetação nas margens; proximidade às residências e construções; presença de resíduos sólidos nas margens e leito; alterações antrópicas no leito; fluxo, volume de água e profundidade similares. A seleção destes pontos foi baseada nas possíveis descargas de efluentes, proximidade aos principais bairros, maior equidistância entre os pontos, foz (confluência com o córrego Ribeirão Preto) e facilidade de acesso.

Foram realizadas duas campanhas para coleta das amostras: no período seco e no período chuvoso (setembro, 2013 e fevereiro, 2014). Nas duas campanhas as amostras foram coletadas em um único dia no período matutino, entre as $08 \mathrm{~h} 00$ e $12 \mathrm{~h} 00$. 


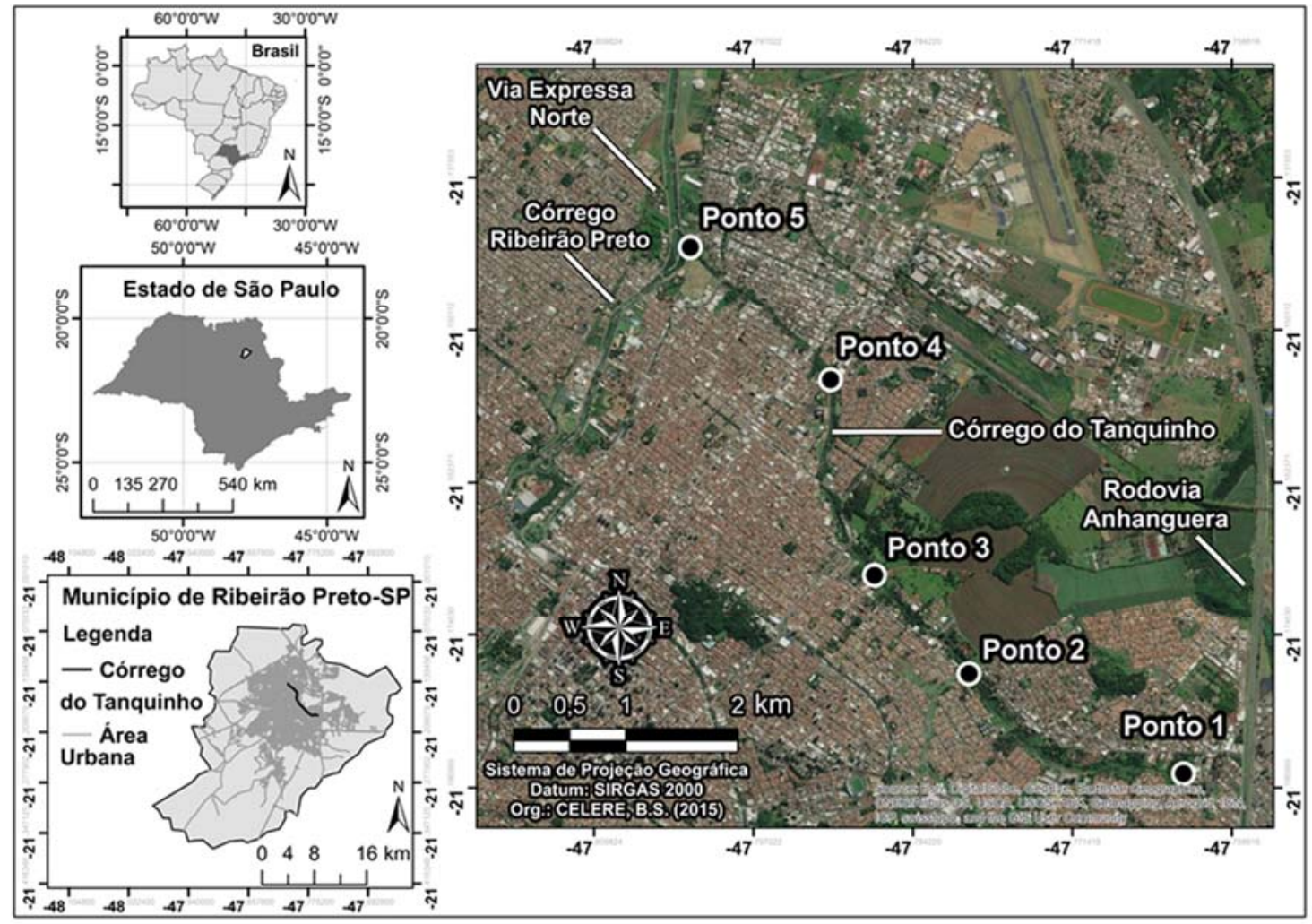

Figura 1. Córrego do Tanquinho destacando os cinco pontos de amostragem, no município de Ribeirão Preto, SP, Brasil.

\subsection{Parâmetros limnológicos}

As medições dos parâmetros limnológicos foram realizadas in situ. As amostras de água foram coletadas em balde de aço inox previamente ambientado no local e analisadas imediatamente.

As leituras de $\mathrm{pH}$ foram executadas com medidor de $\mathrm{pH}$ (marca PH-TEK, modelo $\mathrm{pH} 100$ ). As leituras de temperatura foram executadas com termômetro digital (marca MINIPA, modelo MV365). A turbidez foi determinada utilizando um turbidímetro portátil (marca HANNA ${ }^{\circledR}$, modelo HI 93703). A medição da condutividade foi realizada utilizando um condutivímetro (marca LT Lutron, modelo CD-4303). O teor de oxigênio dissolvido (OD) foi mensurado por meio de um oxímetro (marca Lutron, modelo DO-5510).

Foi registrada uma medição para cada parâmetro em todos os pontos de coleta nas duas campanhas realizadas. Outras medições não registradas foram realizadas apenas para estabilização e/ou calibração dos equipamentos conforme instrução dos manuais.

\subsection{Metais}

Os recipientes utilizados na coleta e armazenamento de amostras eram de polietileno e foram previamente submergidos em solução de ácido nítrico a $30 \%$ por $24 \mathrm{~h}$ para a eliminação de metais interferentes (APHA et al., 2012). As amostras de água foram retiradas da superfície (entre 0 e $30 \mathrm{~cm}$ da lâmina d'água) com auxílio de balde de aço inox previamente ambientado no local, ou, quando possível, coletadas diretamente em recipiente de polietileno de $50 \mathrm{~mL}$ utilizados para preservação e armazenamento. As amostras de sedimento foram coletadas com Draga de Eckman e mantidas à temperatura ambiente por 30 dias em caixas de polietileno, no Laboratório de Ecotoxicologia e Parasitologia Ambiental da Escola de Enfermagem de Ribeirão Preto (EERP)/USP. 
Nas amostras de águas superficiais, adicionou-se ácido nítrico de alta pureza (65\% Suprapur-Merk, Germany) para a fixação dos metais $(\mathrm{pH}<2)$. As amostras foram mantidas a $-18^{\circ} \mathrm{C}$ até o momento da dosagem (APHA et al., 2012).

Para a análise das amostras de sedimento utilizou-se Água Régia ( $\mathrm{HNO}_{3}$; HCL; 3:1). Aproximadamente $0,5 \mathrm{~g}$ de cada amostra foram colocados em bombas de teflon e adicionados $10 \mathrm{ml}$ de Água Régia. As bombas de teflon foram vedadas, deixadas em repouso por $8 \mathrm{~h}$ à temperatura ambiente e posteriormente digeridas a $80^{\circ} \mathrm{C}$ durante $8 \mathrm{~h}$. Após o término da digestão as amostras foram filtradas (Whatman Grade No 40) e diluídas a $25 \mathrm{ml}$ com água Milli-Q (MILLIPORE Direct-Q ${ }^{\circledR} 3$ UV).

Após o pré-tratamento, as amostras de sedimento e água superficial foram encaminhadas para o Setor de Metais do Hospital das Clínicas da Faculdade de Medicina de Ribeirão Preto (FMRP/USP), para as dosagens de Cromo $(\mathrm{Cr})$, Chumbo $(\mathrm{Pb})$, Cobre $(\mathrm{Cu})$, Manganês $(\mathrm{Mn})$, Cádmio $(\mathrm{Cd})$ e Zinco $(\mathrm{Zn})$. As dosagens de $\mathrm{Cr}, \mathrm{Pb}, \mathrm{Mn}$ e $\mathrm{Cd}$ foram realizadas por Espectrofotometria de Absorção Atômica com Forno de Grafite (EAA- FG) em um Espectrofotômetro VARIAN - ZEEMAN (Modelo 640-Z). As dosagens de Zn e Cu foram realizadas por Espectrofotometria de Absorção Atômica de Chama (EAA - chama) em um Espectrofotômetro VARIAN, (Modelo AA-200).

Foram utilizados padrões certificantes de água não potável (NW 556; NW 567; NW 572) do Instituto Quality Control Technologies Pty Ltd., Queensland, Austrália.

\subsection{Análise microbiológica}

A coleta e análise das amostras para avaliação de coliformes totais e Escherichia coli foram executadas de acordo com APHA et al. (2012) e da Companhia Ambiental do estado de São Paulo - CETESB (2011), utilizando a técnica dos Tubos Múltiplos com utilização de substrato cromogênico definido $\left(\right.$ Colilert $\left.^{\circledR}\right)$. Os resultados foram obtidos em Número Mais Provável em $100 \mathrm{~mL}\left(\mathrm{NMP} \mathrm{mL}^{-1}\right)$.

\subsection{Análise dos dados}

Os resultados obtidos com as avaliações limnológicas, microbiológicas e dos metais pesados em água superficial foram comparados com os valores máximos permissíveis da Resolução CONAMA N N $^{357 / 2005}$ que classifica os corpos de água em 5 classes principais, considerando o uso da água e o risco para a saúde pública: classe especial, classe 1, classe 2, classe 3, classe 4 (CONAMA, 2005). De acordo com essa legislação o Córrego do Tanquinho é classificado como classe 2. As águas da classe 2 são destinadas ao abastecimento para consumo humano, após tratamento convencional; à proteção das comunidades aquáticas; à recreação de contato primário, tais como natação, esqui aquático e mergulho; à irrigação de hortaliças, plantas frutíferas e de parques, jardins, campos de esporte e lazer, com os quais o público possa vir a ter contato direto; e à aquicultura e à atividade de pesca. Visto que o Brasil não estabelece valores máximos permissíveis para sedimento em rios e córregos, foram considerados parâmetros internacionais para análise de sedimento. A Resolução CONAMA $n^{\circ} 344 / 2004$, a qual estabelece as diretrizes gerais do material dragado em águas jurisdicionais brasileiras (CONAMA, 2004), também foi utilizada na análise dos dados.

A análise estatística foi realizada por meio do software SPSS Statistics Base 17.0. Os dados que apresentaram distribuição normal (paramétricos) foram submetidos ao teste $t$ de Student para verificar se houve diferença estatística significativa $(\mathrm{p} \leq 0,5)$ entre as duas campanhas de coleta. Já os dados que não apresentaram distribuição normal (não paramétricos) foram submetidos ao Teste de Mann-Whitney. O Teste r- Spearman foi utilizado para verificar correlações entre os parâmetros analisados em água $(p \leq 0,05)$. As concentrações de metais que 
apresentaram valores abaixo do limite de detecção (LD) foram consideradas como metade do valor do limite de detecção (LD/2) para realização dos cálculos.

\section{RESULTADOS E DISCUSSÃO}

\subsection{Parâmetros limnológicos}

Os resultados obtidos na avaliação dos parâmetros limnológicos: $\mathrm{pH}$, temperatura, turbidez, condutividade e OD nos períodos seco e chuvoso estão apresentados na Tabela 1.

Tabela 1. Parâmetros limnológicos em amostras de água do Córrego do Tanquinho, Ribeirão Preto, SP, Brasil, durante os períodos seco e chuvoso.

\begin{tabular}{cccccc}
\hline \multicolumn{5}{c}{ Período Seco } \\
\hline Pontos de Coleta & $\mathrm{pH}$ & $\begin{array}{c}\text { Temperatura } \\
\left({ }^{\circ} \mathrm{C}\right)\end{array}$ & $\begin{array}{c}\text { Turbidez } \\
(\mathrm{FTU})\end{array}$ & $\begin{array}{c}\text { Condutividade } \\
\left(\mu \mathrm{S} \mathrm{cm}^{-1}\right)\end{array}$ & $\begin{array}{c}\text { Oxigênio Dissolvido } \\
\left(\mathrm{mg} \mathrm{L}^{-1}\right)\end{array}$ \\
\hline 1 & 7,0 & 21,3 & 5,6 & 128,5 & $3,3^{*}$ \\
2 & 6,9 & 22,2 & 11,5 & 213 & $3,2^{*}$ \\
3 & 7,0 & 24,4 & 6,5 & 197 & $4,8^{*}$ \\
4 & 6,8 & 26 & 14,9 & 224 & 5,6 \\
5 & 6,6 & 26,8 & 7,1 & 247 & $3,2^{*}$ \\
Média & 6,8 & 24,1 & 9,1 & 201,9 & 4,0 \\
DP & 0,2 & 2,4 & 3,9 & 44,9 & 1,1 \\
Máximo & 7,0 & 26,8 & 14,9 & 247 & 5,6 \\
Mínimo & 6,6 & 21,3 & 5,6 & 128,5 & 3,2 \\
\hline & & & Período Chuvoso & & 4,9 \\
\hline 1 & 6,5 & 24,3 & 1,5 & 135 & $4,8^{*}$ \\
2 & 6,2 & 24,8 & 12,9 & 186,8 & $4,9^{*}$ \\
3 & 6,2 & 26,4 & 11,0 & 185,3 & $4,0^{*}$ \\
4 & 6,2 & 28,8 & 23,1 & 214 & 4,7 \\
5 & 6,4 & 29,9 & 6,1 & 227 & 0,8 \\
Média & 6,3 & 26,7 & 10,9 & 189,6 & 5,9 \\
DP & 0,1 & 2,6 & 8,1 & 35,4 & 4,0 \\
Máximo & 6,5 & 29,8 & 23,1 & 227 & 135 \\
Mínimo & 6,2 & 24,2 & 1,5 & - & \\
VMP & $6,0 \mathrm{a} 9,0$ & - & $\leq 100$ & 5,0 & \\
\hline
\end{tabular}

VMP: Valor máximo permitido pela resolução CONAMA nº 357/2005 para águas classe 2;

-: Não há VMP estabelecido;

*: Valor em desacordo com o VMP.

Os valores de $\mathrm{pH}$ encontram-se dentro dos limites estabelecidos pela Resolução CONAMA $\mathrm{n}^{\mathrm{o}} 357 / 2005$. Comparando os valores de $\mathrm{pH}$ dos períodos seco e chuvoso, foi encontrada diferença estatística significativa $(\mathrm{p}<0,05)$, onde foi observado redução do $\mathrm{pH}$ no período chuvoso. Esse resultado é condizente com os trabalhos de Purandara et al. (2012) e Bayram et al. (2013), e pode ser explicado pelo aumento de matéria orgânica e de outros resíduos carreados pelas chuvas. Além disso, o período chuvoso ocorre no verão, e à medida que a temperatura aumenta ocorre a ionização da água, o que estimula a concentração de íons de hidrogênio e a 
redução no pH (Bayram et al., 2013). Entretanto, essa relação entre pH e temperatura foi melhor observada no período seco onde foi encontrada correlação negativa $(r=-0,821)$ significativa $(\mathrm{p}<0,05)$ entre $\mathrm{pH}$ e temperatura.

A variação da temperatura ao longo do córrego foi similar nos dois períodos. Isso se deve ao fato de que as campanhas de coleta foram realizadas em horários muito semelhantes. A temperatura ambiente aumentava ao decorrer da coleta, refletindo a variação diária da temperatura. Como mostrado na Tabela 1, a condutividade apresentou menor valor no ponto 1 , aumentando de maneira constante ao longo do córrego, com exceção do ponto 2 que, nos dois períodos, foi maior que o ponto 3. Sabe-se que o aumento de condutividade ao longo do rio pode estar relacionado ao acúmulo de cargas poluidoras lançadas por efluentes, ao aporte de cargas poluidoras difusas provenientes do escoamento superficial, e ao acúmulo de íons e sólidos dissolvidos (Purandara et al., 2012). A ausência de vegetação nas margens observada no córrego facilita o aporte de materiais por escoamento superficial.

Foi observada correlação positiva $(\mathrm{r}=0,900)$ e significativa $(\mathrm{p}<0,05)$ entre temperatura e condutividade em ambos os períodos. $\mathrm{O}$ aumento da temperatura pode promover o aumento de sólidos dissolvidos e alguns íons dissociados, que podem elevar a condutividade (Wilbers et al., 2014). Também foi constatada correlação negativa $(r=-0,975)$ significativa $(p<0,05)$ entre condutividade e $\mathrm{pH}$, mas apenas no período seco. Isso pode estar relacionado ao aumento de íons dissociados ao longo do córrego, como íons $\mathrm{H}+$, que podem promover simultaneamente o aumento da condutividade e a redução do $\mathrm{pH}$.

Os valores de turbidez encontrados no córrego do Tanquinho encontram-se dentro do limite estabelecido pela legislação. O aumento da turbidez é decorrente de elevadas cargas de material em suspensão, as quais estão associadas ao lançamento de esgotos domésticos e industriais e ao aporte de cargas difusas provenientes principalmente do escoamento superficial (CESTESB, 2012; Siqueira et al., 2012). Os maiores níveis de turbidez encontrados nos pontos 2 e 4, coincidem com as maiores quantidades de Coliformes Totais e E. coli encontradas (Tabela 2). Isso evidencia a relação direta entre o aumento da turbidez e a provável grande quantidade de efluentes sanitários na água que é indicada pela elevada presença de Coliformes Totais e E. coli. Essa relação é corroborada pela correlação positiva significativa $(\mathrm{p}<0,05)$ observada entre a turbidez e Coliformes Totais (seca: $r=0,975$; chuva: $r=0,900$ ) e a E. coli (seca e chuva: $r=0,900)$.

Como observado na Tabela 1 , apenas o ponto 4 (período seco) e o ponto 1 (período chuvoso) apresentaram OD acima de $5 \mathrm{mg} \mathrm{L}^{-1}$, estando os outros pontos em desacordo com a legislação (CONAMA, 2005). Diminuições nas concentrações de OD em água estão diretamente relacionadas ao aumento da quantidade de matéria orgânica proveniente de efluentes domésticos, industriais e fontes difusas (Alvani et al., 2011). Dessa maneira, poderíamos esperar que o ponto 1 , devido às suas características já descritas, apresentasse os maiores valores de OD, o que foi observado apenas no período chuvoso. Uma das explicações para os baixos valores de OD no ponto 1 pode estar relacionada a baixa vazão e fluxo de água no local, principalmente no período seco, que embora não tenham sido mensuradas, essas características podem estar presentes no ponto 1 como já mencionado. A velocidade da correnteza exerce influência sobre a concentração de OD na água, uma vez que o aumento do fluxo de água leva ao aumento da turbulência, da aeração e, consequentemente, da solubilidade do oxigênio (Krupek et al., 2008).

Embora o período chuvoso tenha apresentado maior concentração de OD em quatro dos cinco pontos de coleta, não houve diferença estatística significativa $(p>0,05)$ entre os valores dos dois períodos de coleta. Valores maiores de OD podem ser esperados no período chuvoso já que o maior fluxo e volume de água promovem diluição da matéria orgânica, aeração e 
aumento da turbulência, como já observado por Tomazelli et al. (2010), no córrego do Tanquinho, e por Purandara et al. (2012).

Foi observada no período chuvoso uma correlação negativa $(\mathrm{r}=-1,000)$ e significativa $(\mathrm{p}<0,05)$ entre o OD e a condutividade, evidenciando a presença de fatores que podem, simultaneamente, promover o aumento da condutividade e a diminuição do OD. Grande quantidade de matéria orgânica pode ser um fator causador dessa correlação, já que está relacionada à diminuição do oxigênio dissolvido (Alvani et al., 2011) e ao aumento da condutividade (Purandara et al., 2012).

\subsection{Análise microbiológica}

A Tabela 2 mostra os resultados da análise de coliformes totais e E. coli nos períodos seco e chuvoso.

O grupo de bactérias coliformes está entre os principais micro-organismos utilizados como indicadores de poluição de origem fecal e é utilizado de forma universal na verificação de presença ou ausência de agentes patogênicos na água e no estabelecimento de padrões de qualidade (WHO, 2011; Wilbers et al., 2014). Dessa forma, os valores de coliformes totais encontrados no Córrego do Tanquinho indicam que esse corpo hídrico possui elevada carga de poluição microbiológica, com destaque para os pontos 2 e 4 (Tabela 2), possivelmente proveniente de descargas irregulares de esgoto doméstico. Porém, os coliformes totais incluem gêneros que não são de origem exclusivamente fecal, como Citrobacter, Enterobacter $e$ Klebsiela, e que podem se desenvolver na água, em solos e plantas, o que limita sua utilização como indicador específico de contaminação fecal (WHO, 2011). Assim, o escoamento superficial e a lavagem do solo pelas chuvas podem contribuir nos valores de coliformes totais no Córrego do Tanquinho. No entanto, é provável que o lançamento de efluentes contribua com a maior parte dos coliformes totais encontrados no córrego, uma vez que foram encontradas quantidades elevadas de E. coli, o que será abordado no próximo item da discussão. Além disso, o valor encontrado nos pontos 2 e $4\left(1,30 \mathrm{E}+07 \mathrm{NMP} 100 \mathrm{~mL}^{-1}\right)$ se aproximam às concentrações encontradas por Tonani (2011) em amostras de esgoto bruto (in natura) da Estação de Tratamento de Esgoto de Ribeirão Preto - ETE/RP. Em duas das amostras analisadas por Tonani (2011) foram encontrados 1,30E+07 de NMP $100 \mathrm{~mL}^{-1}$ de coliformes totais, mesmo valor encontrado no ponto 2 em ambos os períodos, e no ponto 4 no período seco. A presença de elevadas quantidades de coliformes totais é comum em rios que passam por locais densamente urbanizados, como destacado por Wilbers et al. (2014).

Comparando os valores encontrados durante os dois períodos, não foi observada diferença estatística significativa $(p>0,05)$. A média dos valores encontrados foi ligeiramente maior no período seco. Embora a chuva promova o deslocamento de detritos e materiais orgânicos das margens, o que pode aumentar a contaminação por coliformes; o aumento do fluxo, da vazão e do volume de água promove a diluição dos poluentes (Lemos et al., 2010; CETESB, 2012).

A Resolução CONAMA 357/2005 estabelece valores máximos permitidos para coliformes termotolerantes e admite que a E. coli seja determinada em substituição ao parâmetro, seguindo limites estabelecidos pelo órgão ambiental competente (CONAMA, 2005). Com exceção da E. coli, as bactérias que compõem o grupo dos coliformes termotolerantes não são de origem exclusivamente fecal, o que pode comprometer a detecção da poluição fecal. Dessa forma, a E. coli vem sendo cada vez mais utilizada no Brasil e no mundo como principal indicador de poluição fecal em ambientes aquáticos, já que é a única bactéria representante dos coliformes termotolerantes que tem origem exclusivamente fecal e está presente nas fezes humanas e de animais homeotérmicos (Hathaway et al., 2014).

Os resultados de E. coli obtidos foram comparados aos padrões estabelecidos pela CETESB na Decisão de Diretoria nº 027/2013/E de 09/04/2013 (CETESB, 2013). 
Tabela 2. Coliformes totais e E. coli no Córrego do Tanquinho, Ribeirão Preto, SP, Brasil, nos períodos seco e chuvoso - expressos em NMP $100 \mathrm{~mL}^{-1}$.

\begin{tabular}{|c|c|c|}
\hline \multicolumn{3}{|c|}{ Período Seco } \\
\hline Pontos de Coleta & Coliformes totais & Escherichia coli \\
\hline 1 & $2,30 \mathrm{E}+05$ & $7,80 \mathrm{E}+04$ \\
\hline 2 & $1,30 \mathrm{E}+07$ & $9,40 \mathrm{E}+05$ \\
\hline 3 & $4,90 \mathrm{E}+05$ & $2,30 \mathrm{E}+05$ \\
\hline 4 & $1,30 \mathrm{E}+07$ & $1,70 \mathrm{E}+06$ \\
\hline 5 & $4,90 \mathrm{E}+06$ & $1,70 \mathrm{E}+05$ \\
\hline Média & $6,32 \mathrm{E}+06$ & $6,24 \mathrm{E}+05$ \\
\hline DP & $6,37 \mathrm{E}+06$ & $6,92 \mathrm{E}+05$ \\
\hline Máximo & $1,30 \mathrm{E}+07$ & $1,70 \mathrm{E}+06$ \\
\hline Mínimo & $2,30 \mathrm{E}+05$ & $7,80 \mathrm{E}+04$ \\
\hline \multicolumn{3}{|c|}{ Período Chuvoso } \\
\hline 1 & $1,70 \mathrm{E}+06$ & $1,70 \mathrm{E}+05$ \\
\hline 2 & $1,30 \mathrm{E}+07$ & $1,30 \mathrm{E}+06$ \\
\hline 3 & $4,60 \mathrm{E}+06$ & $2,30 \mathrm{E}+05$ \\
\hline 4 & $7,90 \mathrm{E}+06$ & $3,40 \mathrm{E}+05$ \\
\hline 5 & $3,30 \mathrm{E}+06$ & $2,20 \mathrm{E}+05$ \\
\hline Média & $6,10 \mathrm{E}+06$ & $4,52 \mathrm{E}+05$ \\
\hline DP & $4,48 \mathrm{E}+06$ & $4,78 \mathrm{E}+05$ \\
\hline Máximo & $1,30 \mathrm{E}+07$ & $1,30 \mathrm{E}+06$ \\
\hline Mínimo & $1,70 \mathrm{E}+06$ & $1,70 \mathrm{E}+05$ \\
\hline VMP & - & 600 \\
\hline
\end{tabular}

VMP: Valor máximo permitido pela CETESB na Decisão de Diretoria $n^{\circ}$ 027/2013/E de 09/04/2013;

-: Não há VMP estabelecido.

Em todas as amostras analisadas, nos dois períodos, os valores de NMP $100 \mathrm{~m} \mathrm{~L}^{-1}$ ultrapassaram o limite de $600 \mathrm{NMP} 100 \mathrm{~m} \mathrm{~L}^{-1}$ estabelecido para rios de classe 2. O ponto 1 , local com menor quantidade de E. coli encontrada, apresentou NMP $100 \mathrm{~mL}^{-1}$ equivalente a $78.000(7,80 \mathrm{E}+04)$ no período seco e $170.000(1,7 \mathrm{E}+05)$ no período chuvoso (Tabela 2). No ponto 1 (local mais protegido em relação a todo leito do córrego), a detecção de E. coli tem grande importância sanitária, pois indica possível contaminação de origem animal silvestre e incremento de agentes patogênicos ao ser humano (WHO, 2011; Gasparotto, 2011). Por ser o ponto mais próximo à nascente, eram esperados valores menores para E. coli. Gasparotto (2011) realizou estudos em nascentes urbanas na cidade de Piracicaba, SP, Brasil, e encontrou 1600 NMP $100 \mathrm{~m} \mathrm{~L}^{-1}$ na nascente mais contaminada, valor muito inferior ao encontrado na nascente do Córrego do Tanquinho (78.000 NMP $100 \mathrm{~m} \mathrm{~L}^{-1}$ ). Pela sua localização no espaço urbano e industrial, o ponto 1 recebe resíduos e lixo provenientes das galerias pluviais, que escoam a água da chuva para a parte canalizada do córrego.

Os pontos 2 e 4 apresentaram os maiores valores de NMP $100 \mathrm{~m} \mathrm{~L}^{-1}$ para E. coli nos dois períodos (Tabela 2). Isto indica que, próximo a esses pontos, podem estar sendo lançadas 
elevadas cargas de esgoto doméstico, o que compatibiliza com a caracterização desses pontos e da bacia densamente urbanizados, como já mencionado.

O saneamento básico e a boa gestão da água são de grande importância para a saúde pública e, apesar dos avanços nas pesquisas, projetos e obras de saneamento, o número de mortes relacionadas a agentes patogênicos presentes na água ainda é elevado (Wilkes et al., 2011). A alta densidade de E. coli e coliformes totais encontrada no Córrego do Tanquinho pode indicar um alto grau de contaminação das águas, podendo transmitir doenças de veiculação hídrica como cólera, amebíase, giardíase, leptospirose, hepatite infecciosa, febre tifoide, paratifoide, diarreia aguda (Javed et al., 2014).

Os resultados das análises microbiológicas mostraram que as águas do Córrego do Tanquinho representam riscos para população. Além das enchentes que podem ocorrer no córrego (Tomazelli et al., 2010) e colocar a água em contato com a população, há relatos de pessoas, inclusive crianças, que fazem uso do córrego para pesca ou outros fins recreacionais. Essas práticas são comuns em córregos da cidade, e já foram observadas por Da Silva Alves et al. (2013) em estudo realizado no córrego Ribeirão Preto, principal curso de água superficial municipal.

Comparando os valores encontrados para E. coli nos períodos seco e chuvoso, não foi observada diferença estatística significativa $(p>0,05)$. Os resultados foram maiores no período chuvoso em três pontos (Tabela 2), porém a média dos valores encontrados foi maior no período seco devido principalmente ao alto valor encontrado no ponto 4. A lavagem do solo pelas chuvas poderia aumentar a contaminação por E. coli no córrego (O’Neill et al., 2013), já que as fezes de animais presentes nas margens podem ser deslocadas para o leito do rio. Entretanto, a provável elevada carga de esgoto recebida próximo ao ponto 4 , somada ao menor volume de água no período seco, o que resulta em menor diluição de poluentes, fizeram com que a média do de NMP $100 \mathrm{~mL}^{-1}$ fosse alta no período seco.

Como já discutido, foi observada correlação positiva entra os parâmetros microbiológicos e a Turbidez.

\subsection{Metais}

As concentrações dos metais analisados na água superficial do Córrego do Tanquinho, durante os períodos seco e chuvoso estão apresentadas na Tabela 3.

As concentrações de $\mathrm{Cu}$ estavam em desacordo com a legislação nos pontos 4 $\left(0,010 \mathrm{mg} \mathrm{L}^{-1}\right)$ e $5\left(0,011 \mathrm{mg} \mathrm{L}^{-1}\right)$ no período seco, e no ponto $4\left(0,015 \mathrm{mg} \mathrm{L}^{-1}\right)$ do período chuvoso. $\mathrm{O} \mathrm{Cu}$ é encontrado naturalmente em rochas, na água e no ar, e é um micronutriente importante para todos os organismos. Entretanto, em altas concentrações na água, o $\mathrm{Cu}$ pode se tornar tóxico, principalmente para plantas aquáticas (Nagajyoti et al., 2010). Além disso, o $\mathrm{Cu}$ pode ser lançado no ambiente por atividades antropogênicas e atingir os corpos hídricos por meio de resíduos industriais, como observado por Harguinteguy et al. (2014), que encontraram elevadas concentrações de $\mathrm{Cu}$ e outros metais no rio Suquía (Argentina) próximo a uma área de lançamento de efluentes industriais. Dessa forma, embora este metal seja encontrado naturalmente no ambiente e possa ser levado ao córrego por águas da chuva, altas concentrações de $\mathrm{Cu}$ observadas no ponto 4 , tanto no período seco como no chuvoso permitem supor o lançamento de resíduos industriais, haja visto a presença de industrias na bacia do córrego.

$\mathrm{O} \mathrm{Cu}$ e o $\mathrm{Zn}$ foram os únicos metais analisados no córrego que apresentaram correlação significativa $(\mathrm{p}<0,05)$ com $\mathrm{pH}$. Essa correlação foi negativa $(\mathrm{r}=-0,975)$ e observada apenas no período seco. $\mathrm{O}$ pH exerce grande influência na partição de metais entre as fases dissolvida e particulada. Nas águas naturais o $\mathrm{pH}$ é regido pelo equilíbrio carbonato-bicarbonato-dióxido de carbono e, quanto mais alto o valor de $\mathrm{pH}$, maior a quantidade de íons carbonato e bicarbonato. Os metais pesados são removidos da água (fase dissolvida) por precipitados de 
carbonato e bicarbonato. Logo, o aumento do $\mathrm{pH}$ pode provocar a diminuição da concentração de metais pesados na água (Duc et al., 2013).

Tabela 3. Concentração dos metais pesados $\left(\mathrm{mg} \mathrm{L}^{-1}\right)$ analisados na água superficial, do Córrego do Tanquinho, Ribeirão Preto, SP, Brasil, durante os períodos seco e chuvoso.

\begin{tabular}{ccccccc}
\hline \multicolumn{7}{c}{ Período Seco } \\
\hline Pontos de coleta & $\mathrm{Cu}$ & $\mathrm{Zn}$ & $\mathrm{Cr}$ & $\mathrm{Pb}$ & $\mathrm{Cd}$ & $\mathrm{Mn}$ \\
\hline Ponto 1 & 0,004 & 0,00032 & 0,0016 & 0,00053 & $\mathrm{ND}$ & 0,0014 \\
Ponto 2 & 0,0065 & 0,0028 & 0,0026 & 0,0024 & $\mathrm{ND}$ & 0,015 \\
Ponto 3 & 0,003 & 0,0026 & 0,0025 & 0,00035 & $\mathrm{ND}$ & 0,0014 \\
Ponto 4 & $0,010^{*}$ & 0,012 & 0,0021 & 0,00066 & 0,000013 & 0,0057 \\
Ponto 5 & $0,011^{*}$ & 0,014 & 0,0018 & 0,0026 & $\mathrm{ND}$ & 0,0071 \\
Média & 0,0069 & 0,0063 & 0,0021 & 0,0013 & 0,000013 & 0,00612 \\
\hline & & Período Chuvoso & & & \\
\hline Ponto 1 & 0,007 & 0,001 & 0,00084 & 0,0018 & $\mathrm{ND}$ & $0,46^{*}$ \\
Ponto 2 & 0,008 & 0,002 & 0,00091 & 0,00079 & $\mathrm{ND}$ & 0,054 \\
Ponto 3 & 0,009 & $\mathrm{~N} . \mathrm{D}$ & 0,00073 & 0,0017 & $\mathrm{ND}$ & 0,048 \\
Ponto 4 & $0,015^{*}$ & 0,001 & 0,00063 & 0,00057 & $\mathrm{ND}$ & 0,042 \\
Ponto 5 & 0,005 & 0,03 & 0,00054 & 0,0017 & 0,000065 & 0,032 \\
Média & 0,0088 & 0,0085 & 0,00073 & 0,0065 & 0,000065 & 0,1272 \\
VMP & 0,009 & 0,18 & 0,05 & 0,01 & 0,001 & 0,1 \\
\hline
\end{tabular}

VMP: Valor máximo permitido pela resolução CONAMA n $357 / 2005$ para águas classe 2;

ND: Não detectado;

*: Valor em desacordo com o VMP.

A concentração de Mn observada no ponto 1 no período chuvoso $\left(0,46 \mathrm{mg} \mathrm{L}^{-1}\right)$ é próxima à concentração máxima $\left(0,528 \mathrm{mg} \mathrm{L}^{-1}\right)$ encontrada por Jabeen et al. (2014) em água superficial próxima a um parque industrial na bacia Haripur do Paquistão. Valores similares já foram encontrados em análises realizadas no córrego Monte Alegre e em seus afluentes, também localizados no município de Ribeirão Preto. Nikaido et al. (2004) encontraram 0,49 mg.L $\mathrm{L}^{-1} \mathrm{de}$ Mn em sua concentração máxima no córrego Monte Alegre e Alves et al. (2010) obtiveram a concentração máxima de $0,229 \mathrm{mg} \mathrm{L}^{-1}$. A presença do $\mathrm{Mn}$ em águas superficiais pode ser devido a processos naturais como erosão de minerais e reações de oxirredução na interação entre sedimento e água que também podem liberar Mn na água (Abesser e Robinson, 2010). Foi observada diferença estatística significativa $(p<0,05)$ entre o período seco e chuvoso em relação às concentrações de $\mathrm{Mn}$, as quais foram maiores no período chuvoso. Isso pode ter ocorrido por alterações nas reações de oxirredução entre o sedimento depositado no fundo e a coluna d'água, já que as concentrações de Mn no sedimento se apresentaram de maneira inversa a da água. No período seco o Mn apresentou maior concentração no sedimento (Tabela 3) e menor concentração na água e no período chuvoso, o inverso. O Mn absorvido em altas 
concentrações pode ser tóxico e causar disfunções neurais e problemas no sistema nervoso central, como o Alzheimer e o Manganismo (Dieter et al., 2005).

A Resolução CONAMA n ${ }^{0}$ 344/2004 estabelece as diretrizes gerais e os procedimentos mínimos para avaliação do material a ser dragado em águas jurisdicionais brasileiras. Para a classificação do sedimento a resolução define critérios a partir de dois níveis. O nível 1 define os limiares abaixo dos quais prevê-se baixa probabilidade de efeitos adversos à biota e o nível 2 define o limiar acima do qual prevê-se um provável efeito adverso à biota (CONAMA, 2004).

As concentrações dos metais pesados analisados em sedimento no Córrego do Tanquinho, durante o período seco e chuvoso, estão apresentadas na Tabela 4.

Tabela 4. Concentração dos metais pesados $\left(\mathrm{mg} \mathrm{kg}^{-1}\right)$ analisados no sedimento do Córrego do Tanquinho, Ribeirão Preto, SP, Brasil, durante o período seco.

\begin{tabular}{lcccccc}
\hline \multicolumn{7}{c}{ Período Seco } \\
\hline Pontos de coleta & $\mathrm{Cu}$ & $\mathrm{Zn}$ & $\mathrm{Cr}$ & $\mathrm{Pb}$ & $\mathrm{Cd}$ & $\mathrm{Mn}$ \\
\hline Ponto 1 & 32,33 & 128,93 & 532,06 & 0,47 & 0,023 & 669,39 \\
Ponto 2 & 28,3 & 125,49 & 15,11 & 0,33 & 0,018 & 207,2 \\
Ponto 3 & 56,03 & 88,95 & 337,25 & 0,86 & 0,024 & 302,81 \\
Ponto 4 & 52,04 & 66,84 & 57,29 & 0,56 & 0,022 & 703,51 \\
Ponto 5 & 53,69 & 106,44 & 450,72 & 0,83 & 0,022 & 499,18 \\
Média & 44,48 & 103,33 & 278,49 & 0,61 & 0,02 & 476,42 \\
\hline & & & Período Chuvoso & & & \\
\hline Ponto 1 & 34,69 & 36,86 & 8,2 & 1,42 & 0,012 & 32,18 \\
Ponto 2 & 22,57 & 66,82 & 8,76 & 6,59 & 0,024 & 74,49 \\
Ponto 3 & 66,73 & 72,96 & 27,36 & 9,12 & 0,03 & 198,11 \\
Ponto 4 & 40,63 & 87,58 & 20,27 & 9,16 & 0,031 & 112,73 \\
Ponto 5 & 35,55 & 84,42 & 21,73 & 7,15 & 0,04 & 61,23 \\
Média & 40,04 & 69,73 & 17,26 & 6,69 & 0,03 & 95,75 \\
VMP Nível 1 & 35,7 & 123 & 37,3 & 35 & 0,6 & - \\
VMP Nível 2 & 197 & 315 & 90 & 91,3 & 3,5 & - \\
\hline
\end{tabular}

VMP: Valor máximo permitido pelo CONAMA 344/2004 para os níveis 1 e 2;

-: Não há VMP estabelecido.

Com exceção do $\mathrm{Cr}$, todos os metais analisados nos sedimentos apresentaram concentrações abaixo do limite estabelecido pela legislação para o nível 2. O Cr apresentou concentração superior a $90 \mathrm{mg} \mathrm{kg}^{-1}$ (nível 2) nos pontos 1,3 e 5 do período seco. Em contrapartida, no período chuvoso, o $\mathrm{Cr}$ não apresentou concentração superior ao limite do nível 2 e nem ao limite do nível 1, que é de $37,3 \mathrm{mg} \mathrm{kg}^{-1}$. Essa diferença na concentração de $\mathrm{Cr}$ entre os períodos foi estatisticamente significativa $(\mathrm{p}<0,05)$.

Altas concentrações de $\mathrm{Cr}$ e outros metais nos sedimentos de rios podem estar relacionadas à grande quantidade de minerais no sedimento, variando entre regiões com tipos de solos e minerais diferentes (Kelley e Hudson, 2007). Portanto, características minerais locais poderiam influenciar as altas concentrações de Cr nos sedimentos do Córrego do Tanquinho. Alves et al. (2010) também encontraram elevadas concentrações de Cr no córrego Monte Alegre do município de Ribeirão Preto. No entanto é importante salientar sobre a possibilidade de lançamento irregular de efluentes industriais, já que bairros industriais estão presentes na bacia 
do córrego, inclusive próximo ao ponto 1 , onde foi encontrada a maior concentração de Cr nos sedimentos. $\mathrm{O} \mathrm{Cr}$ pode estar presente em vários tipos de resíduos industriais oriundos da produção de têxteis, da fabricação de produtos químicos, da metalurgia básica, dentre outros (Jesus et al., 2004).

As concentrações de $\mathrm{Zn}$ também foram significativamente $(\mathrm{p}<0,05)$ maiores no período seco, com a maior concentração ocorrendo no ponto 1. Comparando os valores encontrados, o Zn apresentou-se acima do limite estabelecido para o nível 1 apenas nos pontos 1 e 2 do período seco. O menor fluxo e volume de água do período seco, principalmente no ponto 1 , facilitam a decantação de partículas em suspensão. Os metais que entram no ambiente aquático podem se ligar a essas partículas que decantam e se incorporar ao sedimento (Jesus et al., 2004). Por outro lado, na chuva, o maior fluxo de água e velocidade da correnteza podem revolver o sedimento e diminuir a concentração de metais no mesmo. Isso pode explicar as maiores concentrações de alguns metais no sedimento durante período seco, com destaque para o ponto 1 .

$\mathrm{O} \mathrm{Pb}$ foi único metal analisado em sedimento que apresentou maiores concentrações na chuva, com diferença estatística significativa $(\mathrm{p}<0,05)$. As concentrações de $\mathrm{Pb}$ de maneira geral foram baixas e não ultrapassaram os limites estabelecidos pela legislação para o nível 1.

Os metais podem atingir o ambiente aquático de forma descontínua, o que pode prejudicar a identificação da contaminação apenas em análises de água. O sedimento pode retratar condições históricas das influências antropogênicas sobre os corpos d'água, por isso vem sendo utilizado cada vez mais em avaliações ambientais (Roig et al., 2011).

\section{CONCLUSÃO}

Os resultados obtidos com o diagnóstico espacial e temporal do Córrego do Tanquinho mostraram que o corpo d'água recebe cargas poluidoras que afetam suas condições físico-químicas e microbiológicas.

Entre os parâmetros limnológicos analisados destaca-se o OD, com concentrações abaixo do limite estabelecido pela legislação.

As concentrações de coliformes totais e E. coli encontradas ao longo do córrego indicaram alta contaminação por esgotos domésticos. Grandes quantidades de E. coli pressupõe a presença de micro-organismos patogênicos que podem causar doenças de veiculação hídrica.

Entre os metais analisados na água superficial, apenas o $\mathrm{Cu}$ e o $\mathrm{Mn}$ apresentaram concentrações acima dos limites estabelecidos pela legislação. Nos sedimentos, destacou-se o Cr, em desacordo com a legislação em algumas amostras. Embora as altas concentrações de Cr e Mn possam estar relacionadas às características do solo da região, podem também indicar, juntamente com $\mathrm{Cu}$, possíveis lançamentos de efluentes industriais no córrego.

A influência temporal na qualidade da água não foi observada em todos os parâmetros analisados. Os parâmetros que apresentaram diferença estatística significativa $(p<0,05)$ entre os períodos seco e chuvoso foram o $\mathrm{pH}$, os metais $\mathrm{Mn}$ e $\mathrm{Cr}$ analisados em água superficial e os metais $\mathrm{Mn}, \mathrm{Cr}$ e $\mathrm{Pb}$ analisados em sedimentos do córrego.

O diagnóstico espacial destaca os pontos 2 e 4 com as piores condições microbiológicas, os pontos 4 e 5 com presença de alguns metais na água acima dos limites estabelecidos pela legislação.

É recomendada a realização de outros estudos que possam esclarecer melhor a origem das cargas poluidoras que afetam o córrego, e também, que o enquadramento do Córrego do Tanquinho seja revisto, buscando analisar se a classe 2 é a ideal para o contexto no qual está inserido esse corpo hídrico e tendo em vista também a sua importância para sociedade. Independente disso é imprescindível que as autoridades públicas conscientizem a população

Rev. Ambient. Água vol. 12 n. 2 Taubaté - Mar. / Apr. 2017 
sobre os riscos em utilizar as águas do córrego de maneira indevida, visto que, na atual situação, podem gerar graves problemas de saúde pública.

Os dados gerados com o presente trabalho podem contribuir com as autoridades públicas e órgãos gestores dos recursos hídricos não só com um possível reenquadramento do córrego e a conscientização da população, mas também em decisões que venham a ocorrer no sentido de recuperar e proteger o Córrego do Tanquinho.

\section{AGRADECIMENTOS}

Ao Conselho Nacional de Desenvolvimento Científico e Tecnológico (CNPq) pela concessão de bolsa de iniciação científica, e à Fundadação de Amparo à Pesquisa do Estado de São Paulo (FAPESP) pelo auxílio regular (Processo No 2013/07238-2).

\section{REFERÊNCIAS}

ABESSER, C.; ROBINSON, R. Mobilisation of iron and manganese from sediments of a Scottish upland reservoir. Journal of Limnology, v. 69, n. 1, p. 42-53, 2010. http://dx.doi.org/10.3274/JL10-69-1-04

ALVANI, J.; BOUSTANI, F.; TABIEE, O.; HASHEMI, M. The effects of human activity in Yasuj Area on the health of Stream city. International Journal of Social, Behavioral, Educational, Economic and Management Engineering, v. 50, p. 341-345, 2011.

ALVES R. I.; TONANI, K. A. A.; NIKAIDO, M.; CARDOSO, O. O.; TREVILATO, T. M. B.; SEGURA-MUÑOZ, S. I. Avaliação das concentrações de metais pesados em águas superficiais e sedimentos do Córrego Monte Alegre e afluentes, Ribeirão Preto, SP, Brasil. Ambiente e Água, v. 5, n. 3, p. 122-132, 2010. http://dx.doi.org/10.4136/ambiagua.157.

AMERICAN PUBLIC HEALTH ASSOCIATION; AMERICAN WATER WORKS ASSOCIATION; WATER ENVIRONMENT FEDERATION. Standard Methods for examination of water and wastewater. 22th. ed. Washington, 2012. $1360 \mathrm{p}$.

BAYRAM, A.; ÖNSOY, H.; BULUT, V. N.; AKINCI, G. Influences of urban wastewaters on the stream water quality: A case study from gumushane province, Turkey. Environmental Monitoring and Assessment, v. 185, n. 2, p. 1285-1303, 2013. http://dx.doi.org/10.1007/s10661-012-2632-y

COMPANHIA AMBIENTAL DO ESTADO DE SÃO PAULO. Águas superficiais: relatório de qualidade das águas superficiais do Estado de São Paulo. 2012. Disponível em http://www.cetesb.sp.gov.br/agua/aguas-superficiais/35-publicacoes-/-relatorios. Acesso em: 22 jul. 2015

COMPANHIA AMBIENTAL DO ESTADO DE SÃO PAULO. Decisão de Diretoria 112/2013/E, de 9 de abril de 2013. Dispõe sobre o estabelecimento dos valores limites do parâmetro Escherichia coli (E.coli), para avaliação da qualidade dos corpos de águas do território do Estado de São Paulo. Diário Oficial do Estado de São Paulo, São Paulo, SP, 12 abr. 2013.

COMPANHIA AMBIENTAL DO ESTADO DE SÃO PAULO. Guia nacional de coleta e preservação de amostras: água, sedimento, comunidades aquáticas e efluentes líquidos. São Paulo: CETESB; Brasília: ANA, 2011. 
CONSELHO NACIONAL DO MEIO AMBIENTE (Brasil). Resolução no 344 de 25 de março de 2004. Estabelece as diretrizes gerais e os procedimentos mínimos para a avaliação do material a ser dragado em águas jurisdicionais brasileiras, e dá outras providências. Diário Oficial [da] União, n. 87, 07 maio 2004, p. 56-57.

CONSELHO NACIONAL DO MEIO AMBIENTE (Brasil). Resolução n 357, de 17 de março de 2005. Dispõe sobre a classificação dos corpos de água e diretrizes ambientais para o seu enquadramento, bem como estabelece as condições e padrões de lançamento de efluentes, e dá outras providências. Diário Oficial [da] União, n. 53, 18 mar. 2005, p. 58-63.

DA SIlVA AlVES, R. I.; CARDOSO, O. O.; TONANI, K. A. A.; JUliÃO, F. C.; TREVILATO, T. M. B.; SEGURA-MUNÕZ, S.I. Water quality of the Ribeirão Preto Stream, a watercourse under anthropogenic influence in the southeast of Brazil. Environmental Monitoring and Assessment, v. 185, p. 1151-1161, 2013. http://dx.doi.org/10.1007/s10661-012-2622-0

DIETER, H. H.; BAYER, T. A.; MULTHAUP, G. Environmental Copper and Manganese in the Pathophysiology of Neurologic Diseases (Alzheimer's Disease and Manganism). Acta hydrochimica et hydrobiologica, v. 33, n. 1, p. 72-78, 2005. http://dx.doi.org/10.1002/aheh.200400556

DUC, T. A.; LOI, V. D.; THAO, T. T. Partition of heavy metals in a tropical river system impacted by municipal waste. Environmental Monitoring and Assessment, v. 185, n. 2, p. 1907-1925, 2013. http://dx.doi.org/10.1007/s10661-012-2676-z

GASPAROTTO, F. A. Avaliação ecotoxicológica e microbiológica da água de nascentes urbanas no município de Piracicaba - SP. 2011. 90 p. Dissertação (Mestrado em Ciências) - Centro de Energia Nuclear na Agricultura, Universidade de São Paulo, Piracicaba, 2011.

HARGUinteguY, C. A.; CIRELLI, A. F.; PIGNATA, M. L. Heavy metal accumulation in leaves of aquatic plant Stuckenia filiformis and its relationship with sediment and water in the Suquía river (Argentina). Microchemical Journal, v. 114, p. 111-118, 2014. http://dx.doi.org/10.1016/j.microc.2013.12.010

HATHAWAY, J. M.; KROMETIS, L. H.; HUNT, W. F. Exploring Seasonality in Escherichia coli and Fecal Coliform Ratios in Urban Watersheds. .Journal of Irrigation and Drainage Engineering, v. 140, n. 4, p. 04014003-1-04014003-6, 2014. http://dx.doi.org/10.1061/(ASCE)IR.1943-4774.0000700

JABEEN, S.; SHAH, M. T.; AHMED, I.; KHAN, S.; HAYAT, M. Q. Physico-chemical parameters of surface and ground water and their environmental impact assessment in the Haripur Basin, Pakistan. Journal of Geochemical Exploration, v. 138, p. 1-7, 2014. http://dx.doi.org/10.1016/j.gexplo.2013.12.004

JAVED, F.; AHMED, N. M.; SHAH, H. U.; IQBAL, M. S.; WAHID, A. ; AHMAD, S. S. Effects of Seasonal Variations on Physicochemical Properties and Concentrations of Faecal Coliform in River Kabul. World Applied Sciences Journal, v. 29, n. 1, p. $142-$ 149, 2014. http://dx.doi.org/10.5829/idosi.wasj.2014.29.01.2080 
JESUS, H. C. de; COSTA, E. de A.; MENDONÇA, A. S. F.; ZANDONADE, E. Distribution and abundance of heavy metals in sediments from Vitória Island estuarine system. Química Nova, v. 27, n. 3, p. 378-386, 2004. http://dx.doi.org/10.1590/S010040422004000300004

KELLEY, K. D.; HUDSON, T. Natural versus anthropogenic dispersion of metals to the environment in the Wulik River area, western Brooks Range, northern Alaska. Geochemistry: Exploration, Environment, Analysis, v. 7, n. 1, p. 87-96, 2007. http://dx.doi.org/10.1144/1467-7873/06-121

KRUPEK, R. A.; BRANCO, C. C. Z.; PERES, C. K. Variação sazonal de alguns parâmetros físicos e químicos em três rios pertencentes a uma bacia de drenagem na região centrosul do Estado do Paraná, Sul do Brasil. Acta Scientiarum Biological Sciences, v. 30, n. 4, p. 431-438, 2008. http://dx.doi.org/10.4025/actascibiolsci.v30i4.5873

LEMOS, M.; FERREIRA NETO, M.; DIAS, N. da S. Sazonalidade e variabilidade espacial da qualidade da água na Lagoa do Apodi, RN. Engenharia Agrícola e Ambiental, v. 14, n. 2, p. 155-164, 2010.

MEI, K.; LIAO, L.; ZHU, Y.; LU, P.; WANG, Z.; DAHLGREN, R. A.; ZHANG, M. Evaluation of spatial-temporal variations and trends in surface water quality across a rural-suburbanurban interface. Environmental Science and Pollution Research, v. 21, n. 13, p. 80368051, 2014. http://dx.doi.org/10.1007/s11356-014-2716-z

NAGAJYOTI, P. C.; LEE, K. D.; SREEKANTH, T. V. M. Heavy metals, occurrence and toxicity for plants: a review. Environmental Chemistry Letters, v. 8, n. 3, p. 199-216, 2010. http://dx.doi.org/10.1007/s10311-010-0297-8

NIKAIDO, M.; OLIVEIRA, A. DA S.; TREVILATO, T. M. B.; SEGURA-MUÑOZ, S. I. Análise da qualidade da água do córrego Monte Alegre e afluentes, Ribeirão Preto, SP, Brasil: enfoque para coliformes fecais e metais pesados. Mundo saúde, v. 28, n. 4, p. 414-420, 2004.

O’NEILL, S.; ADHIKARI, A. R.; GAUTAM, M. R.; ACHARYA, K. Bacterial contamination due to point and nonpoint source pollution in a rapidly growing urban center in an arid region. Urban Water Journal, v. 10, n. 6, p. 411-421, 2013.

PHILIPPI JR, A.; MARTINS G. Águas de Abastecimento. In: PHILIPPI JR., A. Saneamento, saúde e ambiente: fundamentos para um desenvolvimento sustentável. Barueri: Manole, 2005.

PURANDARA, B. K.; VARADARAJAN, N.; VENKATESH, B.; CHOUBEY,V. K. Surface water quality evaluation and modeling of Ghataprabha River, Karnataka, India. Environmental Monitoring and Assessment, v. 184, p. 1371-1378, 2012. http://dx.doi.org/10.1007/s10661-011-2047-1

RIBEIRÃO PRETO. Secretaria Municipal da Administração. Plano municipal de saneamento básico. 2012. Disponível em: http://www.ribeiraopreto.sp.gov.br/sadm/aud/pmsb_01_ 2012.pdf. Acesso em: 08 nov. 2015

ROIG, N.; NADAL, M.; SIERRA, J. et al. Novel approach for assessing heavy metal pollution and ecotoxicological status of rivers by means of passive sampling methods. Environment International, v. 37, n. 4, p. 671-677, 2011. http://dx.doi.org/10.1016/j.envint.2011.01.007 
SHIN, J. Y.; ARTIGAS, F.; HOBBLE, C.; LEE, Y. S. Assessment of anthropogenic influences on surface water quality in urban estuary, northern New Jersey: Multivariate approach. Environmental Monitoring and Assessment, v. 185, n. 3, p. 2777-2794, 2013. http://dx.doi.org/10.1007/s10661-012-2748-0

SIQUEIRA, G. W.; APRILE, F.; MIGUEIS, A. M. Diagnóstico da qualidade da água do rio Parauapebas (Pará - Brasil). Acta Amazonica, v. 42, n.3, p. 413-422, 2012.

SOUZA, C. L. de; ANDRADE, C. S.; SOUZA, C. L. de; ANDRADE, C. S. Health, environment and territory: a necessary discussion in health training. Ciência \& Saúde Coletiva, v. 19 , n. 10 , p. 4113-4122, 2014. http://dx.doi.org/10.1590/1413812320141910.08992014

TOMAZELLI, A. C.; LOPES, D. C.; FERRACINI JUNIOR, R. Avaliação da qualidade da água do córrego Tanquinho (Ribeirão Preto, SP, Brasil). Revista do Centro Universitário Barão de Mauá, v. 3, p. 32-42, 2010.

TONANI, K. A. A. Bioagentes patogênicos em águas residuárias: destaque para Giardia spp., Cryptosporidium spp., bactérias indicadoras e vírus entéricos. 2011.140 p. Tese (Doutorado em Ciências) - Escola de Enfermagem de Ribeirão Preto, Universidade de São Paulo, Ribeirão Preto, 2011.

WORLD HEALTH ORGANIZATION. Guidelines for drinking-water quality. 4th. ed. Genebra, 2011.

WILBERS, G. J.; BECKER, M.; NGA, L. T.; SEBESVARI, Z.; RENAUD, F. G. Spatial and temporal variability of surface water pollution in the Mekong Delta, Vietnam. Science of the Total Environment, v. 485-486, p. 653-665, 2014.

http://dx.doi.org/10.1016/j.scitotenv.2014.03.049

WILKES, G.; EDGE, T. A.; GANNON, V. P. J.; et al. Associations among pathogenic bacteria, parasites, and environmental and land use factors in multiple mixed-use watersheds. Water Research, v. 45, n. 18, p. 5807-5825, 2011. http://dx.doi.org/10.1016/j.watres.2011.06.021 